\title{
Effect of Film-Induced Stress on Mechanical Properties at Stress Corrosion Cracking Tip
}

\author{
Yang Hongliang, Xue He, Yang Fuqiang, Zhao Lingyan
}

Xi'an University of Science and Technology, Xi'an 710054, China

\begin{abstract}
Oxide film rupture theory has become one of the most popular models to quantitatively predict the stress corrosion cracking (SCC) rate at crack tip of nickel-based alloys in high temperature and high pressure environments, and stress intensity factor has become an important parameter to measure the stress corrosion cracking rate. In order to further understand the fracture mechanism of the oxide film and the driving force of crack growth, film-induced stress intensity factor was proposed. To understand the effect of film-induced stress intensity factor on the micro-mechanical state at the tip of EAC (environmentally assisted cracking), the stress-strain in the base metal at the EAC tip was simulated and discussed using a commercial finite element analysis code. And then the effect of film-induced stress intensity factor on Mises stress, equivalent plastic strain, tensile stress, tensile strain and tensile plastic strain gradient of crack tip was obtained, which provides a parameter to improve the quantitative predication accuracy of EAC growth rate of nickel-based alloys and austenitic stainless steels in the important structures of nuclear power plants. Therefore the oxide film rupture theory was improved.
\end{abstract}

Key words: stress corrosion cracking; film-induced stress; stress intensity factor; oxide film; nickel-based alloy

Mechanical status at cracking tip of nickel-based alloys and stainless steel SCC for nuclear pressure vessels and steam generators is one of the key factors in the analysis of SCC mechanism and quantitative prediction of crack growth rate $^{[1,2]}$. In the process of SCC, a layer of oxide film can be formed on the crack tip surface of the nickel base alloy ${ }^{[3]}$. Researches ${ }^{[4-6]}$ show that an additional tensile stress, which is induced by the oxide of alloys at crack tip, exists at the substrate side of substrate-oxide film interface. The stress could cause the local plastic deformation at crack tip and intergranular film fracture, leading to the formation of deep crack. Corrosion current density increased and the work function decreased with increasing pre-strains, which facilitated anodic dissolution, thereby resulting in an enhancement of the film growth rate and the film-induced stress ${ }^{[7]}$. Film-induced stress and the residual stress in films deposited by electrolysis are important in the corrosion research and the electrolysis industry ${ }^{[8]}$. Even in the macroscopic com- pressive stress zone, film-induced stress at the crack tip can lead to the initiation and propagation of $\mathrm{SCC}^{[9-11]}$. Stress intensity factor, which reflects the stress field near the crack tip, is an important parameter to characterize the driving force and crack growth rate.

In order to understand the effects of stress intensity factor on the stress-strain field of the crack tip induced by the oxide film of the material for nuclear power plants, the stress-strain fields in the SCC crack tip of nickel-based alloys were analyzed by the sub model technology of ABAQUS. The effects of film-induced stress intensity factor on the stress and strain field of the crack tip of nickel-based alloys SCC were obtained.

\section{Theory Model}

The oxide film at crack tip in the pressurized water reactor was obtained by $\mathrm{SEM}^{[12]}$, as shown in Fig. 1.

The area of crack tip is the oxide film formed on the

Received date: August 25, 2016

Foundation item: National Natural Science Foundation of China (51475362, 11502195); Scientific Research Program Funded by Shaanxi Provincial Education Department (16JK1493)

Corresponding author: Xue He, Ph. D., Professor, Xi'an University of Science and Technology, Xi'an 710054, P. R. China, Tel: 0086-29-83856250, E-mail: xue_he@hotmail.com

Copyright $@ 2017$, Northwest Institute for Nonferrous Metal Research. Published by Elsevier BV. All rights reserved. 


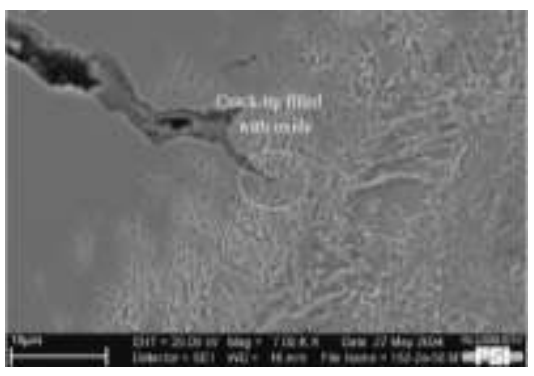

Fig.1 Morphology of oxide film at crack tip

surface of the structural material in the process of corrosion cracking. Fracture mechanism of film-induced stress in stress corrosion cracking can be shown as: Without considering the external load, there is an additional tensile stress at one side of the interface matrix ${ }^{[5]}$. It makes the local plastic deformation at crack tip, and the stress can cause the dislocation emission, which can cause the oxide film intergranular cracks, then leading to the occurrence and extension of stress corrosion cracking. Thus it can form deep matrix crack, and stress corrosion cracking can be produced $^{[9-11]}$.

Therefore, film-induced stress plays an important part in the crack growth driving force. Mechanical factor is one of the three factors that affect the crack growth (mechanics, materials, environment). The concept of stress and strain field at crack tip was proposed by Japanese expert Shoji, and the theoretical calculation formula of strain rate at crack tip was proposed according to the crack tip strain gradient theory and the strain redistribution in the crack growth $^{[13]}$.

$$
\begin{aligned}
& \frac{\mathrm{d} \varepsilon_{\mathrm{ct}}}{\mathrm{d} t}=\left(\frac{\mathrm{d} \varepsilon_{\mathrm{ct}}}{\mathrm{d} a}\right) \cdot\left(\frac{\mathrm{d} a}{\mathrm{~d} t}\right) \\
& \left(\frac{\mathrm{d} \varepsilon_{\mathrm{ct}}}{\mathrm{d} a}\right)=\frac{\partial \varepsilon_{\mathrm{ct}}}{\partial a}-\frac{\partial \varepsilon_{\mathrm{ct}}}{\partial r} \\
& \varepsilon_{\mathrm{ct}}=\beta \cdot\left(\frac{\sigma_{\mathrm{y}}}{E_{0}}\right) \cdot\left[\ln \left(\frac{R_{\mathrm{P}}}{r_{0}}\right)\right]^{1 /(n-1)}
\end{aligned}
$$

where, $\beta$ is constant, $\sigma_{\mathrm{y}}$ is the yield strength of the material, $E_{0}$ is Young's modulus of the material, $r_{0}$ is distance from the crack tip to the front of the crack tip, $K$ is stress intensity factor, $n$ is the hardening exponent for the plastic, $R_{\mathrm{p}}$ is plastic zone size; $R_{\mathrm{p}}=\lambda\left(K / \sigma_{\mathrm{y}}\right)^{2}, \lambda$ is constraint factor.

Due to the change of $r_{0}$ and $K$ in the process of crack propagation, the change of strain at crack tip can be induced. Therefore, the strain rate at crack tip is modified as follows:

$$
\frac{\mathrm{d} \varepsilon_{\mathrm{ct}}}{\mathrm{d} t}=\beta \cdot \frac{\sigma_{\mathrm{y}}}{E_{0}} \cdot \frac{n}{n-1} \cdot\left(2 \frac{\dot{K}}{K}+\frac{\dot{a}}{r_{0}}\right) \cdot\left[\ln \left(\frac{R_{\mathrm{P}}}{r_{0}}\right)\right]^{1 /(n-1)}
$$

The crack growth rate of EAC can be expressed as Eq. (5) by adopting to crack tip strain rate calculation Eq. (4).

$$
\left\{\begin{array}{l}
\frac{\mathrm{d} a}{\mathrm{~d} t}=k_{\mathrm{a}} \cdot\left\{\beta \cdot \frac{\sigma_{\mathrm{y}}}{E_{0}} \cdot \frac{n}{n-1} \cdot\left(2 \frac{\dot{K}}{K}+\frac{\dot{a}}{r_{0}}\right) \cdot\left[\ln \left(\frac{R_{\mathrm{P}}}{r_{0}}\right)\right]^{1 /(n-1)}\right\}^{m} \\
k_{\mathrm{a}}=\frac{M}{Z \rho F} \cdot \frac{i_{0}}{1-m} \cdot\left(\frac{t_{0}}{\varepsilon_{\mathrm{f}}}\right)^{m}
\end{array}\right.
$$

Eq.(5) is the FRI model which combines together mechanics factors, electrochemical environment parameters and material parameters together. This model is based on slip dissolution theory. The crack growth rate of nickel-based alloys in high temperature water environment is quantitatively predicted, and the stress intensity factor $K$ is an important parameter to characterize the fracture of the material.

The stress intensity factor $K$ can be divided into external load stress intensity factor $K_{\mathrm{a}}$ and film-induced stress intensity factor $K_{\mathrm{f}}$ :

$$
K=K_{\mathrm{a}}+K_{\mathrm{f}}
$$

when $K_{\mathrm{a}}+K_{\mathrm{f}}=K_{\mathrm{IC}}$, the $\mathrm{SCC}$ is to nucleating and extending. Under constant load stress corrosion, the film-induced stress is increased, the effective stress of the crack is also increasing, and the plastic strain is developed, and the critical condition causes the nucleation and expansion of the micro crack, which leads to the stress corrosion cracking.

It is usually considered the external load, while ignoring the film-induced stress using of Shoji's equation to predict the crack growth rate. Although $K_{\mathrm{f}}$ is relatively less, it is not negligible in short cracks. According to Eq.(6), $K$ is easier to reach $K_{\mathrm{IC}}$ because of the existence of $K_{\mathrm{f}}$, and the SCC is easier to nucleate and crack.

It can be assumed that the stress intensity factor of rack tip remains unchanged, because the film-induced stress change is relatively small, and the FRI model Eq.(5) can be simplified as Eq. (7). The $K$ increases with the increasing of $K_{\mathrm{f}}$, and the crack growth rate increases according to Eq.(7).

$$
\frac{\mathrm{d} a}{\mathrm{~d} t}=k_{\mathrm{a}}^{1 /(1-m)} \cdot\left[\frac{\beta \sigma_{y} n}{E(n-1)} \cdot \frac{1}{r_{0}} \cdot\left[\ln \left[\frac{\lambda}{r_{0}} \cdot\left(\frac{K}{\sigma_{y}}\right)^{2}\right]\right]^{1 /(n-1)}\right]^{7 /(1-m)}
$$

In the small plastic zone of crack tip, the film-induced stress is more obvious in short crack, the greater the $K_{\mathrm{f}}$, the easier the crack growth, and the main effect is $K_{\mathrm{a}}$ in the long crack. If the crack is long enough, $K_{\mathrm{f}}$ can be ignored. Therefore, $K_{\mathrm{f}}$ is more suitable for short crack propagation.

\section{Finite Element Modeling}

\subsection{Specimen model}

Half inch compact tension specimen (0.5T-CT) was used in this numerical calculation with virtual experiment process according to American Society for Testing and Materials Standard ${ }^{[14]}$. The geometric shape and size of 0.5T-CT specimen are shown in Fig.2. 


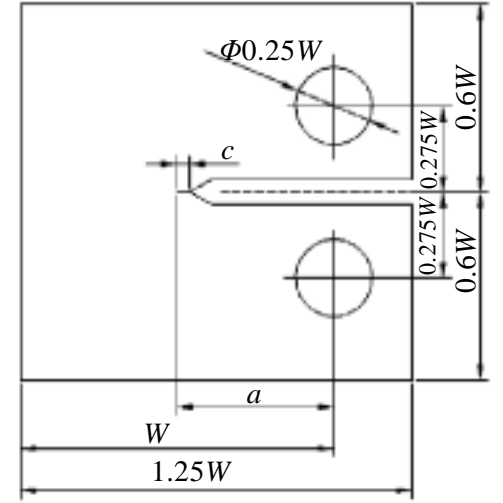

Fig.2 Geometric size of 0.5T-CT specimen ( $W=25 \mathrm{~mm}, a=0.5 \mathrm{~W}$, $c=2 \mathrm{~mm})$

The thickness of oxide film formed by nickel-based alloys in high temperature and high pressure water is about 1 $\mu \mathrm{m}$ to $2 \mu \mathrm{m}^{[15]}$ and $2 \mu \mathrm{m}$ is adopted in research.

\subsection{Material model}

The non linear relationship between stress and strain beyond yield at crack tip of nickel-based alloys is described by Ramberg-Osgood equation in this numerical simulation ${ }^{[16]}$ :

$$
\frac{\varepsilon}{\varepsilon_{0}}=\frac{\sigma}{\sigma_{0}}+\alpha\left(\frac{\sigma}{\sigma_{0}}\right)^{n}
$$

Where, $\varepsilon$ is strain, $\sigma$ is stress, $E$ is Young's modulus of the material, $\sigma_{0}$ is the yield strength of the material, $\alpha$ is the yield offset and $n$ is the hardening exponent for the plastic.

The material parameters of nickel-based alloys and oxide film are shown in Table 1.

\subsection{FE Model}

Taking into account that film-induced stress is caused by internal expansion and is not related to external load, therefore, the film-induced stress is simulated by expansion. Using ABAQUS to calculate stress and strain distribution in crack tip, the base metal and oxide film are set up as a whole, and the different material properties are given in the model. Using the plane deformation model and adopting 8 -node biquadratic plane strain quadrilateral reduced integration, the finite element model is shown in Fig.3. In order to improve the accuracy of the calculation, the oxide film and base metal at crack tip are refined to obtain a more detailed and accurate data.

Table 1 Mechanical properties of alloy 600 and the oxide film formed in PWR primary water at $288^{\circ} \mathrm{C}^{[17,18]}$

\begin{tabular}{ccc}
\hline Material & Alloy 600 & Oxide film \\
\hline Young's modulus, $E / \mathrm{GPa}$ & 189.5 & 140 \\
Poisson's ratio, $v$ & 0.286 & 0.31 \\
Yield strength, $\sigma_{0} / \mathrm{MPa}$ & 436 & - \\
Yield offset, $\alpha$ & 3.075 & - \\
Hardening exponent, $n$ & 6.495 & - \\
\hline
\end{tabular}

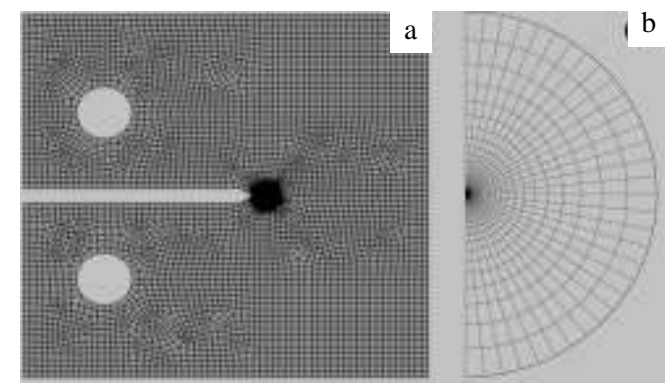

Fig.3 Mesh of 0.5T-CT specimen (a) and the detail around crack tip of sub-model (b)

\section{Results and Discussion}

\subsection{Effect of film-induced stress intensity factor on Mises stress}

Fig. 4 shows the effect of $K_{\mathrm{f}}$ on the Mises stress of the crack tip $-90^{\circ} \sim 90^{\circ}$. It can be seen that the Mises stress of the crack tip increases with the increasing of $K_{\mathrm{f}}$, and the maximum value of Mises stress appears in front of the crack tip.

Fig. 5 shows the effect of $K_{\mathrm{f}}$ on Mises stress in front of the crack tip. From Fig. 5 we can see that with the increasing of $K_{\mathrm{f}}$, the Mises stress at the crack tip also increase, but the larger the distance of the crack tip, the smaller the Mises stress is. It also shows that the reduced rate of Mises stress decreases with the decreasing of $K_{\mathrm{f}}$. This shows that the crack tip is easy to crack and extend.

\subsection{Effect of film-induced stress intensity factor on equivalent plastic strain}

The effect of $K_{\mathrm{f}}$ on the equivalent plastic strain of the crack tip is shown in Fig. 6.

From Fig. 6 we can see that equivalent plastic strain at crack tip increases with the increasing of $K_{\mathrm{f}}$, and the maximum value of equivalent plastic strain appears in the front of the crack tip in the range of $-90^{\circ} \sim 90^{\circ}$.

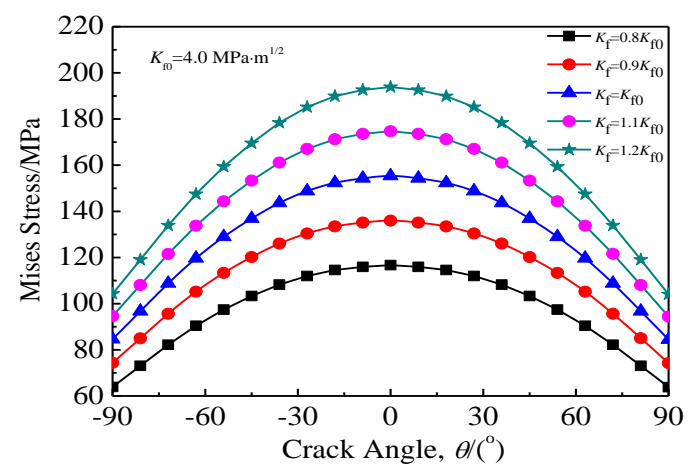

Fig.4 Effect of $K_{\mathrm{f}}$ on Mises stress around crack tip 


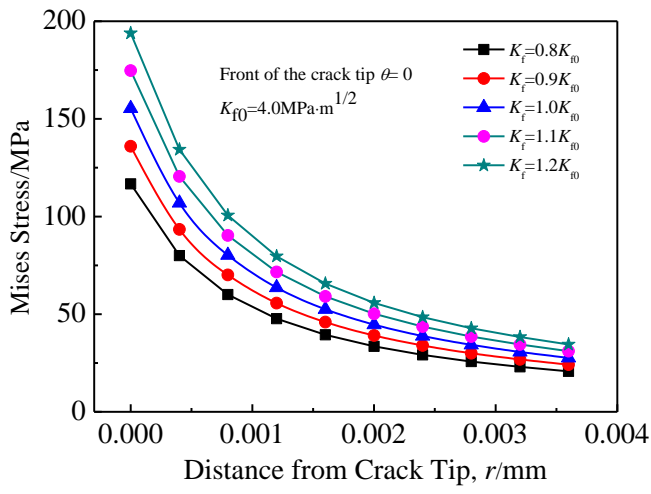

Fig.5 Effect of $K_{\mathrm{f}}$ on Mises stress in front of the crack tip

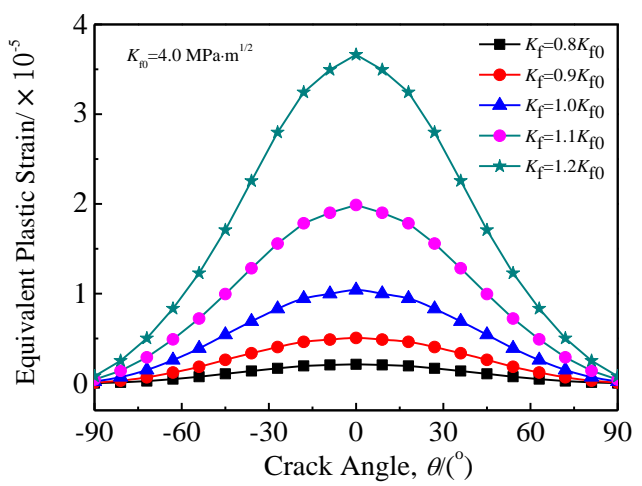

Fig. 6 Effect of $K_{\mathrm{f}}$ on equivalent plastic strain around crack tip

Fig.7 shows the effect of $K_{\mathrm{f}}$ on the equivalent plastic strain in front of the crack tip. It can be seen that the equivalent plastic strain increases with the increasing of $K_{\mathrm{f}}$ in a small range at the crack tip, but equivalent plastic strain decreases rapidly and approaches zero when the distance exceeds the range. This can be explained by Eq.(8).

\subsection{Effect of film-induced stress intensity factor on tensile stress}

Fig. 8 shows the effect of $K_{\mathrm{f}}$ on tensile stress at crack tip. From the figure it can be seen that at the crack tip of about $-45^{\circ} \sim 45^{\circ}$, with the increasing of $K_{\mathrm{f}}$, tensile stress increases gradually, and the maximum value appears in front of the crack tip, and Ni-based alloys is subjected to tensile stress in this range. The base metal is subjected to compressive stress in the range of $-90^{\circ} \sim-45^{\circ}$ and $45^{\circ} \sim 90^{\circ}$. This indicates that the tensile stress corrosion is easy to be generated in the range of $-45^{\circ} \sim 45^{\circ}$, and the crack is most likely to occur at $0^{\circ}$ in the front of the crack tip.

Fig. 9 shows the effect of $K_{\mathrm{f}}$ on tensile stress in the front of crack tip. As can be seen from the figure, the tensile stress increases with the increasing of $K_{\mathrm{f}}$ in front of crack tip. With the increasing of $r$, tensile stress gradually decreases and finally tends to 0 . The greater the $K_{\mathrm{f}}$ and the smaller the $r$, the greater the tensile stress is, and the more easily the crack is produced.

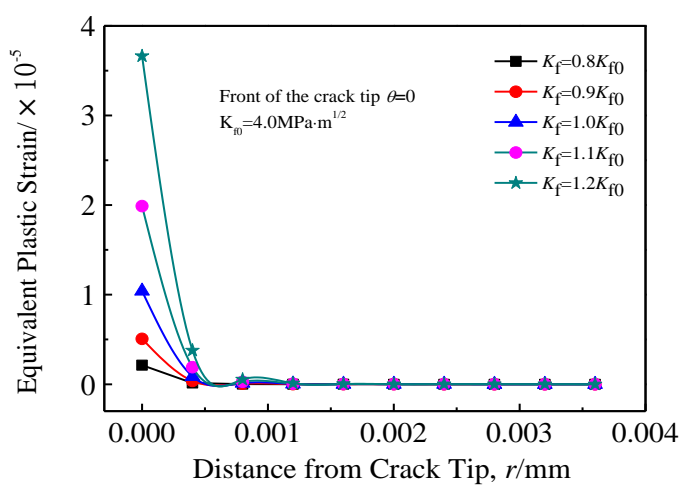

Fig.7 Effect of $K_{\mathrm{f}}$ on PEEQ in front of the crack tip

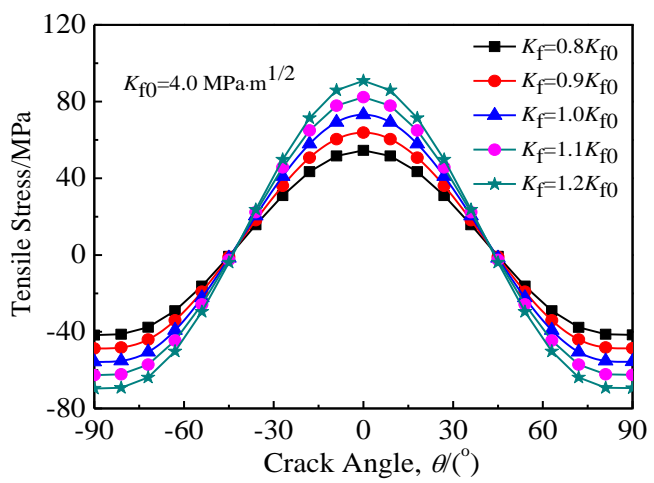

Fig. 8 Effect of $K_{\mathrm{f}}$ on tensile stress around crack tip

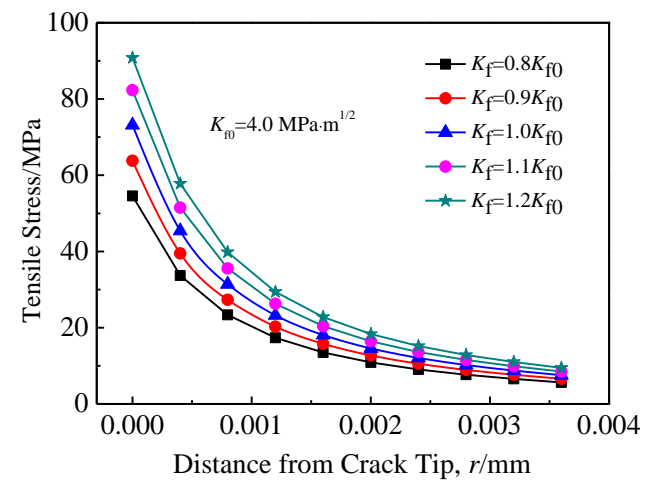

Fig.9 Effect of $K_{\mathrm{f}}$ on tensile stress in front of the crack tip

\subsection{Effect of film-induced stress intensity factor on tensile plastic strain}

Fig. 10 shows the effect of $K_{\mathrm{f}}$ on tensile plastic strain at crack tip. From the figure it can be seen that at the crack tip of $-45^{\circ} \sim 45^{\circ}$, tensile plastic strain increases gradually with the increasing of $K_{\mathrm{f}}$. The maximum value appears in front of the crack tip, and Ni-based alloys is subjected to tensile plastic strain in this range. The tensile strain appears negatively in the range of $-90^{\circ} \sim-45^{\circ}$ and $45^{\circ} \sim 90^{\circ}$, and the amplitude is small. It is indicated that this region suffers 


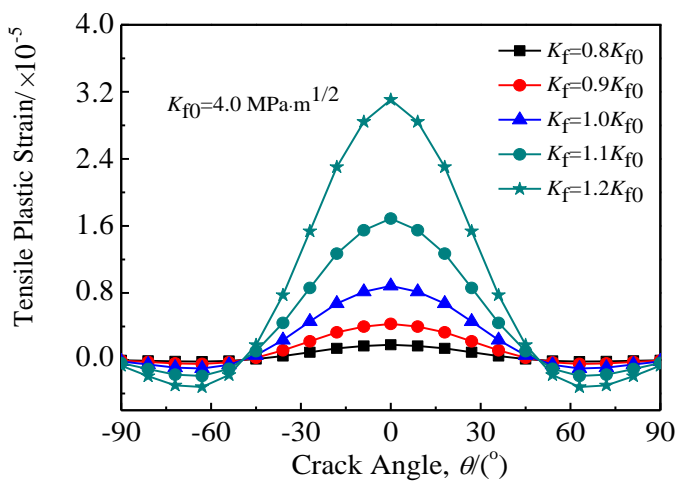

Fig. 10 Effect of $K_{\mathrm{f}}$ on tensile plastic strain around crack tip

compressive stress that results in a small amount of compressive strain.

Effect of $K_{\mathrm{f}}$ on tensile plastic strain at the front of the crack tip is shown in Fig. 11.

Fig. 11 shows that the greater the $K_{\mathrm{f}}$, the greater the tensile strain is. With the increasing of $r$, the tensile plastic strain gradually decreases and finally tends to 0 . This can be explained by Eq. (7).

\subsection{Effect of film-induced stress intensity factor on tensile plastic strain gradient}

On the basis of the Eq.(1) $\sim(4)$, Xue et al. ${ }^{[19,20]}$ proposed a method to replace the crack tip strain rate by the crack tip strain gradient. In the strain gradient model, it is assumed that the crack tip strain is equal to the plastic strain at the front of the crack tip. Ford-Andresen model can be improved to:

$$
\varepsilon_{\mathrm{ct}}=\varepsilon_{\mathrm{p}}
$$

where $\varepsilon_{\mathrm{p}}$ is equivalent plastic strain gradient at the front of the crack tip $r_{0}$. In order to calculate conveniently, the crack tip strain gradient can be calculated by simplified Eq. (10).

$\frac{\mathrm{d} \varepsilon_{\mathrm{p}}}{\mathrm{d} a} \approx \frac{\Delta \varepsilon_{\mathrm{p}}}{\Delta a}=\frac{\varepsilon_{\mathrm{p} 2}-\varepsilon_{\mathrm{p} 1}}{a_{i+1}-a_{i}}$

Fig. 12 shows the effect of $K_{\mathrm{f}}$ on the tensile strain rate at

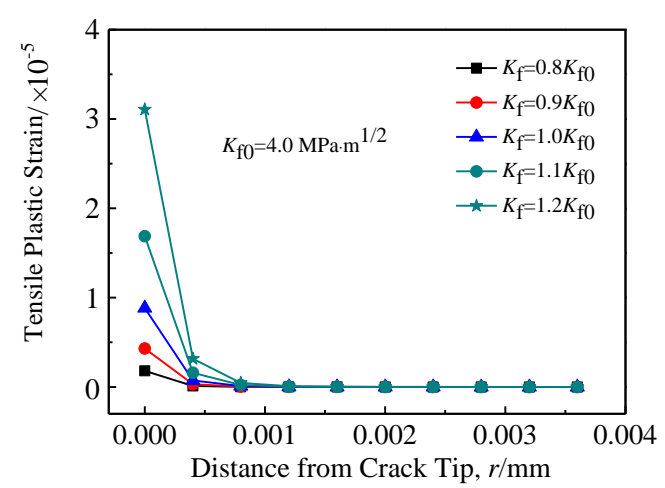

Fig. 11 Effect of $K_{\mathrm{f}}$ on tensile plastic strain in front of the crack tip

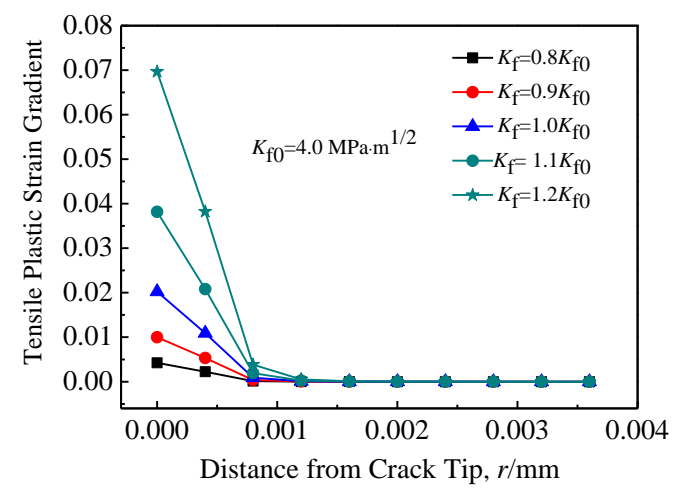

Fig. 12 Effect of $K_{\mathrm{f}}$ on tensile plastic strain gradient in front of the crack tip

the distance $r$ in the front of the crack tip. As can be seen from the figure, tensile strain rate increases with the increasing of stress intensity factor, and crack growth rate is also increasing. This can be explained by Ford-Andresen model Eq. (11). The tensile strain decreases with the increasing of the distance $r$ in the front of the crack tip.

$$
\frac{\mathrm{d} a}{\mathrm{~d} t}=\frac{M}{Z \rho F} \cdot \frac{i_{0}}{1-m}\left[\left(\frac{t_{0} \dot{\varepsilon}_{\mathrm{ct}}}{\varepsilon_{\mathrm{f}}}\right)^{m}-m \cdot \frac{t_{0} \dot{\varepsilon}_{\mathrm{ct}}}{\varepsilon_{\mathrm{f}}}\right]
$$

\section{Conclusions}

1) The stress intensity factor $K$ can be divided into external load stress intensity factor $K_{\mathrm{a}}$ and film-induced stress intensity factor $K_{\mathrm{f}}$. Without considering the external load, the effective stress of the crack increases with the increasing of $K_{\mathrm{f}}$, and promotes the effective of plastic strain. When the critical condition is reached, the nucleation and expansion of micro cracks appear, which leads to stress corrosion cracking. $K_{\mathrm{f}}$ is one of the main factors that can't be ignored in the driving force of stress corrosion crack growth.

2) In front of crack tip, Mises stress, equivalent plastic strain, tensile stress, tensile strain and tensile plastic strain gradient of the crack tip are increased with the increasing of $K_{\mathrm{f}}$ and it is easier to crack. But with the $r$ increasing, Mises stress, equivalent plastic strain, tensile stress, tensile strain and tensile plastic strain gradient gradually decrease, and finally approach to 0 .

3) In a small range around crack tip, Mises stress, equivalent plastic strain, tensile stress, tensile strain and tensile plastic strain gradient of the crack tip are increased with the increasing of $K_{\mathrm{f}}$ and aggravate the stress corrosion cracking rate.

\section{References}

1 Andresen P L, Gott K, Nelson J L. Proceedings of the 9th International Symposium on Environmental Degradation of Materials in Nuclear Power Systems-Water Reactors[C]. Newport Beach, California, 1999: 423 
2 Yassar R S, Scudiero L, Alamr A S et al. Thin Solid Films[J], 2010, 518: 2757

3 Wang Wenwen, Luo Ji, Guo Leichen. Rare Metals[J], 2015, 34: 426

4 Chu Wuyang, Qiao Lijie et al. Hydrogen Embrittlement and Stress Corrosion, Basic Part[M]. Beijing: Science Press, 2013 (in Chinese)

5 Lu H, Gao K W, Chu W Y. Corrosion Science[J], 1998, 40: 1663.

6 Guo X Z, Gao K W, Qiao L J. Corrosion Science[J], 2002, 44: 2367.

7 Du X S, Su Y J, Zhang C et al. Corrosion Science[J], 2013, 69 : 302

8 Yuan W J, Zhang Z L, Su Y J et al. Corrosion Science $[\mathrm{J}]$, 2013, 68: 128

9 Han Enhou, Wang Jianqiu, Wu Xinqiang. Acta Metallurgica Sinica[J], 2010, 46: 1379

10 Sieradzki K, Newman R C. J Phys Chem Solids[J], 1987, 48: 1101

11 Sieradzki K, Newman R C. Phil Mag A[J], 1985, 51: 95
12 Seifert H P, Ritter S, Shoji T et al. Journal of Nuclear Materials[J], 2008, 378: 197

13 Shoji T, Suzuki S, Ballinger R G. Proceedings of the 7th International Symposium on Environmental Degradation of Materials in Nuclear Power Systems[C]. California: Breckinridge, 1995: 881

14 ASTM standard E399-90[S]. 2002

15 Xue He, Xue Xiaofeng, Tang Wei. Rare Metal Materials and Engineering[J], 2011, 40(7): 1188 (in Chinese)

16 Ramberg W, Osgood W R. NACA Tech Note, No. 902[R], 1943

17 Goudeau P, Renault P O, Villain P et al. Thin Solid Films [J], 2001, 398-399: 496

18 Yang Fuqiang, Xue He, Zhao Lingyan et al. Rare Metal Materials and Engineering [J], 2014, 43(2): 513 (in Chinese)

19 Xue He, Sato Y, Shoji T. Journal of Pressure Vessel and Technology, Transactions of the ASME[J], 2009, 131: 61

20 Xue He, Shoji Tetsuo. Journal of Pressure Vessel Technology, Transactions of the ASME[J], 2007, 129: 460

\title{
膜致应力对应力腐蚀裂尖力学特性的影响
}

\author{
杨宏亮, 薛 河, 杨富强, 赵凌燕
}

(西安科技大学, 陕西 西安 710054)

摘 要: 氧化膜破裂理论是目前定量预测核电高温水环境中镍基合金应力腐蚀开裂速率应用最为广泛的理论模型之一, 其中应力强度 因子是衡量应力腐蚀开裂速率的重要参量。为进一步了解氧化膜破裂机理及裂纹扩展驱动力特性, 提出了膜致应力强度因子。为了深 入了解膜致应力强度因子在 EAC (环境致裂) 裂纹扩展过程中裂尖的力学状况, 在不考虑外载的情况下, 从理论和数值模拟两方面分 析研究了 EAC 裂尖基体金属区域的应力应变分布状态，得出了膜致应力强度因子对裂尖 Mises 应力、等效塑性应变、拉伸应力、拉 伸应变及拉伸应变梯度的影响规律，为提高定量预测高温高压水环境中镍基合金及不锈钢 $\mathrm{EAC}$ 扩展速率精度奠定基础，进而完善了 氧化膜破裂机理。

关键词：应力腐蚀; 膜致应力; 应力强度因子; 氧化膜; 镍基合金

作者简介：杨宏亮，男，1981 年生，博士生，西安科技大学，陕西 西安 710054, 电话: 029-83856232, E-mail: hl_yang@163.com 